\title{
Managing or Mismanaging Workforce Diversity: Major Determinants.
}

\author{
Abdulraheem, Issa Ph.D \\ Department of Business and Entrepreneurship, College of Humanities, Management and Social sciences, \\ Kwara State University, Malete, Nigeria
}

\begin{abstract}
The management of workforce diversity is a very sensitive issue and is becoming more visible in management practices. Moreover, workforce diversity is being encouraged by an increased level of national and international laws offering protection against discriminations based on sex, race, disability etc. The perception of management of workforce diversity will determine its successful application and monitoring in order to make it successful. Moreover, the approach to managing diversity that should be adopted may also depend on the characteristics of the society in which it operates. The question is: are all approaches to managing workforce diversity applicable to all organisations irrespective of their cultural orientations? The research objective is to examine the practical application of some the approaches to managing diversity in Nigerian higher education especially in admission and employment. It also examines the understanding and appreciation of having a diverse workforce. The article adopted a single case study approach of Kwara State Polytechnic, Nigeria and used in-depth interview and documentary evidence as major sources of collecting data. It was found that the application of federal character and quota system in managing workforce diversity have some challenges in Nigerian higher education militating against its successful implementation. The article concludes with the argument that inappropriate application of a type of approach by an organisation might result in crisis and could be termed as 'mismanaging' workforce diversity.
\end{abstract}

Key words: Workforce diversity, higher education, federal character, admission and employment.

\section{Introduction}

There are different views on the effects of the present approaches to the management of workforce diversity at Kwara State Polytechnic, Nigeria. While some people believe that it is not the workforce diversity that is a source of problem and crisis in the institution but it is the approach used in the management of workforce diversity. Political consideration as a major determinant of the approach used result in undesirable outcomes. This article therefore examines the effects of the practical application of the diversity programs of the federal government of Nigeria on admissions and employment in Nigerian tertiary institutions using Kwara State Polytechnic as a case study.

The research process involved four stages with each stage informing the next and relevant to the research area. The first is the introduction, the second is the literature review on workforce diversity and the third is the approaches of federal government of Nigeria to managing diversity. The fourth is methodology and the fifth is data analysis process using in-depth interview carried out with three management staff of the polytechnic and. which included documentary evidence of the application of these approaches to federal universities which invariably transient to other federal and state polytechnics while the last part is the conclusion.

2.1 Meaning of Workforce Diversity

\section{Literature Review}

Diversity as a concept [1] has different meanings and applications depending on where you are in the world. Diversity is strategic and can determine the success or failure of an organisation. It is important to handle the issue of diversity seriously. Diversity is a very sensitive issue and if not handled properly it can be detrimental to an organisation [2].

Culture is what distinguishes one group from another and can be understood as 'an expression of all the experiences of a popular people or group over time which help shape their personality and manner of perceiving [3]. Therefore there could be different cultures even within a community such as the case of Nigeria. Culture is considered as a complex series of characteristics, which may be related to nation, political bodies, families, group of people, and an individual [4]. 


\subsection{Approaches to diversity}

There are different and contradictory approaches to diversity according [5]. The various approaches to managing diversity have been divided into four paradigms: Resistance; Discrimination-and fairness; Accessand-legitimacy; and Learning-and-effectiveness [6]. They comprise explicitly different perceptions about diversity, of its importance as well as the internal and external forces influencing its management, ranging from reactive to proactive.

Some organisations are more positive and supportive of diversity than others [7]. While some see the benefits of having a workforce with greater cultural awareness, more points of view, others do not, and even when diversity is acknowledged as important there are different approaches or best practices from different organisations. One way of classifying approaches to diversity is either largely reactive or proactive.

\subsubsection{Reactive approach to diversity}

In the resistance approach, organisations concentrate on enhancing organisational effectiveness and productivity by maintaining demographic and cultural homogeneity and the status quo [8]. It represents a strategically reactive management approach, which fosters assimilation and regards diversity as a non-issue. Where management is based on the enhancement of sameness instead of diversity on the ground of equality legislation and obligation initiative, the organisation can be described as discrimination- and- fairness and being regarded as strategically reactive.

\subsubsection{Proactive approach to diversity}

Although pro-diversity forces argue that organisation performance is enhanced when the workforce's diversity is embraced as an opportunity. But diversity is often discouraged by those who fear that too many perspectives, beliefs, values and attitudes dilute concerted action [9]. In valuing and making use of diversity, there will inevitably be more discussion and disagreement about how things should be done but it was also argues that to manage this, leaders must develop agreed principles of organisational identity and values that will inform the work of individuals without stultifying their creativity or keenness to contribute. Skilled leaders can bring out the talents of others in ways that produce extraordinary results [10].

No organisation's culture is static. As the external and internal factors, which influence culture, change, so culture will change. The society is dynamic and the organisation is part of the society. However, given that culture is locked into the beliefs, values and norms of each individual in the organisation and because these are difficult constructs to alter, this type of organic cultural change will be slow, unless perhaps there is some major shock to the organisation[11]. Moreover, for a variety of reasons, organisations may find that their existing culture is inappropriate or even detrimental to their competitive needs. The federal government of Nigeria failed to realise the dynamic nature of culture and has not reviewed its approaches for almost three decades despite some conspicuous changes in the culture of people of this country.

It is however important that an organisational culture, which values adaptation, by necessity, makes use of a wider range of skills by more members. In order to accomplish the substantial tasks of information gathering and evaluation in complex environments, adaptive organisational cultures must seek information and support from diverse elements within their structure [12]. Culture and shared values are reflected in what is actually given priority in the daily activities of the organisation, as well as those things that actually drive strategy, policy, direction and priority [13]. Organisations constantly study the changes in culture of the society with a view to changing their own strategies to meet the needs of the community

Diversity approach will be most effective when the strategic responses and implementation style fit with management's intent and internal and external pressures [14]. The assimilation approach to managing diversity was identified [15]. This approach ignores differences, and thus no integration efforts are made. Instead, people are expected to assimilate into a pre-defined and dominant culture.

However, culture is always a common achievement and a culture of inclusion depends on the level of mutual recognition [16]. For an inclusive diversity culture approach, it pays respect to the plurality of subcultures inside the corporation that none is excluded from the ongoing moral discourse and that each subculture has the opportunity to take part in shaping the cultural reality in the organisation, its values, norms and policies [17].

Moreover, with inclusionary approach Pless and Maak argued that differences are recognised, valued and engaged. Voices are understood as being legitimate, heard and integrated in decision making and problem solving processes, they have an active role in shaping culture and fostering creativity and innovation and eventually adding value to the company's performance.

Managing diversity is a means of utilising and maximising the individual potential by effectively managing and valuing differences and by creating a culture and atmosphere of respect as a responsible employer in access-and -legitimacy approach [18]. While learning-and-effectiveness paradigm organisations connect diversity to work and employee perspectives, and proactively manage it aiming at fundamental changes in 
thinking, structure, tasks and environment. The target is towards viewing employees as strategic assets, irreplaceable, valuable and as an investment.

For diversity to be a resource, the subcultures must be connected and must learn to value each other enough to learn something of each other's culture and language. A central task for the learning leader is to ensure good cross-cultural communication and understanding throughout the organisation [19].

Managing diversity requires an understanding of the institutional processes in place to deliver strategy, process and support. It is a 'top down' vision of how an organisation can productively manage the demands of the current legal and social environment. In Human Resource Management (HRM) terms, managing diversity is seen as being a more integrated approach [20]. They see managing diversity as a tool for encouraging the integration of HRM strategy areas to deliver the objective of a diverse workforce where difference is valued and recognised throughout all the organisational processes.

The recognition by the institution of the need to manage a more diverse student body whilst also recruiting staff from diverse sources encouraged the development of integrated processes and mainstreaming. Moreover, organisational vision is seen as a key concept in diversity practice. They believe that if diversity is to become a business issue then the organisation must have a clear vision of what it intends to achieve and the message must be clearly communicated that diversity is a business, as opposed to a moral or ethical objective [21] [22].

\subsection{Effective Management of Workforce Diversity}

Productivity is one of the main objectives of managing workforce diversity. It was argued that the successful management of diversity can have positive impact on both tangible measures of organisational effectiveness (e.g. costs and resource acquisition) and intangible dimensions such as creativity and problem solving capacity [23]. Similarly, it was argued that diversity in its many forms can be a source of strength in organisations, but in order to capitalise upon its potential there must be a commitment to exploring differences, fostering understanding and attending to differences by providing opportunities for learning and working together [24].

Seven factors to manage diversity effectively was proposed and summed up in one word as MOSAIC [25]. These are Mission and value, objective and fair processes, skill workforce, aware and fair, active flexibility, individual focus, and culture that empowers. The effective management of diversity recognises that people from different backgrounds, cultures and experiences can bring new ideas to the workforce [26]. They maintain that organisations can include effective management of workforce diversity as one of the criteria on which all managers will be assessed. It was suggested that the diversity of the workforce should be considered an asset to be developed [27].

However, the beginning of managing diversity effectively is to develop a truly multicultural organisation. He described a multi cultural organisation as one, which reflects the contributions and interests of diverse cultural and social groups in its mission, operations, and product or service [28].

\section{Managing Diversity In Nigeria}

Nigeria has a federal system of government primarily because of the diverse culture and ethnic groupings. Although federalism is believed to be well suited to the management of diversity in Nigeria, doubts have been raised about its ability- in its most elaborate form as federal government to solve minority problems, reduce ethnic conflicts or equitably accommodate diversity [29].

However it was argued that federalism has the inherent danger of encouraging and exacerbating ethnic conflicts and therefore keeping a divided society permanently, if not more divided. Nigeria is even more divided because some ethnic groups continue to agitate for recognition [30]. For example, there are pressures from one ethnic group in the state to have their own polytechnic. However, the state does not have the resources to maintain two polytechnics. The federal system of government resulted to the adoption of quota system and federal character with the intention of the government fairness to every citizen. This is a constitutional provision which Kwara State Polytechnic must adopt.

Nigeria is a multicultural, multiethnic and multi-religions country with about 250 different ethnic groups. This cultural diversity transcend to both private and public organisations. The structure of the organisations reflected the diverse people in the country. Ethnic groups are represented in the organisation especially in the public sector. The provision in the 1999 constitution of Nigeria in chapter 11 section 14(3) and (4) stated that the composition of the government should reflect federal character and diversity of people. The intention of the government was to avoid the domination of a few ethnic groups from a few states in government. Therefore, section 153 (c) of the same constitution established the Federal Character Commission.

Nigeria is a country characterised by intense ethnic polarisation and conflict but it is also a country that has creatively, if not always successfully, sought to grapple with its heritage of ethnic diversity and conflict [31]. The composition and location of the institution make it diverse for both staff and students. The Polytechnic 
is located in the state capital, Ilorin. The city is a confluence of cultures, populated by Yoruba, Hausa, Fulani, Nupe, Baruba, Igbo, other Nigerians and foreign nationals, its native cultures are struggling to survive with Christians and Islam on the driving seat. The Polytechnic is state owned and all the cultural groupings in the state must be represented in the affairs of the institution. That led to the necessity to manage cultural diversity in the institution.

\subsection{Major Determinants of Managing or Mismanaging Workforce Diversity}

Political factor and the structure of federalism in Nigeria are major determinant of the reactive approach adopted in managing diversity in the state owned polytechnic. The management of the Polytechnic must yield to political pressures from "political godfathers" in terms of admissions and employments. Therefore, reactive approach was adopted in managing workforce diversity. Whereas in proactive the major determinant is performance through effective range of integrating skills from diverse groups.

Instruments used to achieve successful diversity management include the quota system, federal character, zoning system, catchments areas, and less advantaged or educationally disadvantage areas. The success of the application of quota system and federal character principle in the admission process and employment are majorly determined by political consideration. Approaches adopted are the response to various demands of the people.

\subsubsection{Quota system}

Quota system is desirable in a diverse country and society as Nigeria where diversity needs to be actively and purposefully encouraged and legally enforced as provided by Nigeria's Supreme law, the Constitution of Nigeria. It was explained that the Constitutions of Nigeria, (from 1979 to 1999) for decades now, have made provisions for a Quota System and the reflection of a Federal Character in appointment of public office holders [32]. Similarly it was argued that Federal Character is something which is not only desirable, but also inevitable in a severely-divided society such as Nigeria [33].

Managing diversity in Nigeria was reactive and this approach affected the structures and management of Nigerian higher education. The government therefore, adopted federal system of government to accommodate various and diverse cultural and ethnicity groups in the country. These are features of federalism in operations in Nigeria entrenched in the constitution and which must be implemented by all government establishments. Approaching the problems of culture this way is defensive.

Many authors provided evidence and practical examples of the inappropriateness of using quotas or targets to measure the degree to which organisations have implemented a sophisticated diversity management [34]. It was argued that quota system has been counterproductive in Nigeria because candidates seeking particular placements have tended to manipulate their state of origin in order to gain employment [35].

\subsubsection{Federal Character}

The Nigerian doctrine of 'Federal Character' emerged from the 1979 Constitution, and it calls for the distribution of federal appointments to reflect equitably the different dimensions of the nation's ethnic, regional and religious, heterogeneity, in order to 'promote a sense of belonging and loyalty' among the diverse peoples of Nigeria. Its forerunner is the 'quota system', intended to give opportunities in education and employment to disadvantaged groups and areas in the federation. Since its inception as a formalized doctrine, 'Federal Character' has become a celebrated topic in Nigerian political discourse with its enthusiasts as well as antagonists [36].

The Federal Character Commission was established to ensure that different ethnic groups are fairly represented. This is seen as managing diversity. Federal character has been defined as a variant of consociation principle of proportional representation or quota system where the main objective was to ensure that the kaleidoscope of the country's diversity was reflected in composition of government at all levels [37]. Federal character means looking everywhere for the best and the most competent and therefore there is nothing wrong with the principle. However, the principle may be subverted especially if it is interpreted as a crude form of ethnic balances. In a diverse society like Nigeria, the public service cannot evade the issue of representation [38].

Even though number has important implications for the management of diversity, states with fewer and relatively equal ethnic groups are easier to manage than those with several unequal groups, for example, it is how the difference among the groups manifest that makes diversity problematic [39].

\section{Methodology}

In generating the data, in-depth interview and documentary evidence were used. Three management staff of the polytechnic were interviewed. Documentary evidence from the Federal universities on the application of the approaches to diversity management was used and which invariably transient to other federal 
and state polytechnics. The interview method was used because it provided direct evidence about similarities and differences in participant's opinion [40]. In analysing the data collected categorisation was used. Categorisation was used to make sense of things, to help us see patterns in social interaction [41]. Categorisation is therefore helpful in developing hunches, hypotheses and theories. The purpose is to get multiple perspectives and this will also demonstrate and widens different experiences of life and how society is constructed.

\section{Data Presentation And Analysis}

Table 1 below shows the example of the application of zoning system in Nigeria universities. The admission was based on such principles as educationally less advantaged and catchments areas and not purely based on merits.

Table1 Admissions to Nigerian universities by zone of origin, 2000-2001

\begin{tabular}{|l|l|l|}
\hline Zone & No. of admitted candidates & Percentage of total admissions \\
\hline North west & 2341 & 4.7 \\
\hline North east & 1979 & 3.9 \\
\hline North central & 5597 & 11.1 \\
\hline South west & 8763 & 17.4 \\
\hline South east & 19820 & 39.4 \\
\hline South South & 11734 & 23.3 \\
\hline
\end{tabular}

Source: adapted from www.jambng.com in Mustapha and accessed in September, 2008.

\subsection{Managing diversity in admission}

Kwara State Polytechnic introduced certain measures such as catchments admission policies in order to be ethical and give values to the society. However, values considered essential in one society might be rejected in another culture, and vice visa. The problem of reactive approach in Kwara state Polytechnic is that it is a continuous process-managing crisis as they arise. The advantage of having diverse workforce could not be achieved because management was busy finding solutions to each problem at various times and this is worsening by selfish agitations from employees.

Quota - based admission bears directly on the educational quality. The quota system is designed as follows: the Board reserved 30\% of a polytechnic's admissions for residents of its immediate 'catchments' area, and a further $20 \%$ for the educationally disadvantaged. $10 \%$ of the admissions were made at the discretion of the Rector. Only $40 \%$ of students were admitted based on their academic performance.

The quota -based admissions policy may have made university access more equitably, but it did not necessarily support academic success for those admitted. As a result, although access has increased, university responsiveness to the needs and abilities of a more diverse student body that follows from rising enrolments was limited.

\subsection{Managing diversity in employment}

Employment and promotion at Kwara State Polytechnic are based on quota in the pursuit of federal character. This practice is where eminently qualified persons are often rejected in order to take on those from other areas [42]. Those that oppose to quotas system hinged on the argument that it is counter merit and has negative impact on the efficiency (lower standards) [43]. He said that the support for quotas has been based on the need for stability and even development, as well as equity and fairness. Quota system has had adverse consequences for institutions in terms of disciplines, morale, and overall effectiveness and efficiency [44]. Hence it is counterproductive because candidates seeking particular placements have tended to manipulate their state of origin in order to gain a place [45]. However, quota system of employment sometimes serves as cynosure for the recruitment of the unqualified persons from certain parts of the country [46]. The incompetence of these individuals, to a large extent has led to the inability of strategic organisations to accomplish their mission.

Although the high performing learning organisations require a diverse workforce-workers that represent multiple races, perspectives, intelligences, and knowledge [47]. Similarly many economists view workforce development as a step necessary to improve productivity if one is to advance in a highly competitive global economy underlines their importance [48]. Quota system led to formation of groups with subsequent emergent of leaders that will serve as an opinion leader that will always dictate to the government on behalf of his community. These people are referred to as 'godfather' of that community.

\subsection{Measurement of diversity}

There is no effective measurement of diversity because the institution did not have statistics and up-todate records of workforce diversity. The institution did not have a total autonomy to plan and implement strategies on how to manage cultural diversity but only to implement those policies handed over to it by the 
government through the supervisory ministry, ministry of education, science and technology. The state government set up Education Strategic Plan (ESP) which supports the approach of a State Ministry of Education, Science and Technology (SMOES\&T) to develop education through a whole, or sector wide approach (SWAP).

\subsection{Integration of staff}

The total workforce found it difficult to integrate and work together harmoniously to achieve organisational objectives. There is high level of suspicion partly because some workers forged their local government origin to take advantage of catchments areas or educationally disadvantage areas or they are not competent in their jobs.

Table 2 Categorisation and unitisation of responses from three management staff of Kwara State Polytechnic

\begin{tabular}{|c|c|c|c|c|c|c|}
\hline \multicolumn{7}{|c|}{ Categories } \\
\hline & & & 2 & 4 & & 6 \\
\hline Respondents & $\begin{array}{l}\text { Nature } \\
\text { of } \\
\text { diversity }\end{array}$ & Approach & Methods & Employment & Measurement & Integration \\
\hline $\mathbf{1}$ & 'natural' & Reactive & $\begin{array}{l}\text { Polarised with } \\
\text { political } \\
\text { influence }\end{array}$ & $\begin{array}{l}\text { Quotas } \\
\text { system/federal } \\
\text { character }\end{array}$ & Haphazard & $\begin{array}{l}\text { Not well } \\
\text { integrated }\end{array}$ \\
\hline 2 & ditto & $\begin{array}{l}\text { No specific } \\
\text { method }\end{array}$ & Initiative & Representation & No statistics & $\begin{array}{l}\text { Difficult to } \\
\text { integrate } \\
\text { successfully }\end{array}$ \\
\hline 3 & ditto & $\begin{array}{l}\text { Pressure } \\
\text { from group }\end{array}$ & $\begin{array}{l}\text { Depend on the } \\
\text { management }\end{array}$ & $\begin{array}{l}\text { Godfatherism and } \\
\text { power tussle }\end{array}$ & Not certain & $\begin{array}{l}\text { Suspicious of } \\
\text { each other }\end{array}$ \\
\hline
\end{tabular}

\section{V1. Conclusion}

This research work has been able to examine the factors that may determine the success of various approaches to managing workforce diversity. The political consideration resulted in mismanaging workforce diversity in Nigerian higher education. Effective approaches to diversity management are strategic and focus on goals that are achievable. The application of approaches to workforce diversity might be relevant and serve as solution to the country's problems if the implementation was not influenced by political consideration.

Moreover, changes in the socio-cultural orientation have made the reactive approach to fuel crisis and this could be regarded as mismanagement of diversity. The key to the evolution of a diversity program to integration and learning perspective which produces cultural change is the ability to effectively talk through the dimensions of differences in the organisation. Therefore the major determinant of the reactive approach to managing diversity in the state owned polytechnic is political consideration which always makes the management to yield to political pressures from "political godfathers" in terms of admissions and employments. Whereas in proactive the major determinant is performance through effective range of integrating skills from diverse groups.

\section{References}

[1]. P. Harris. R. Morgan, S Morgan, Managing cultural difference. Global leadership strategies for the $21^{\text {st }}$ century.( Oxford: ElsevierButterwork,2004)

[2]. G, Magdaleno, and B, Kleiner, Global trends in managing cultural diversity. Cross Cultural Management. An International journal. 3:(4), 1996, 31:36.

[3]. R, Rikowski, Knowledge management: social, cultural and theoretical perspectives. (Oxford. Chandos Publishing Limited.,2007)

[4]. P.W.Betts, Supervisory management. $7^{\text {th }}$ edn. (England. Pearson Education Limited, 2000)

[5]. S. Groschl, and L. Doherty, Diversity management in practice. International Journal of Contemporary Hospitality management. 11(6), 1999, 262:268

[6]. A. Sippola, 'Developing culturally diverse organisations; a participative and empowerment-based method'. Women in Management Review. 22 (4), 2007,253:273

[7]. J, Tippers, How to increase diversity through your recruitment practices. Industrial and Commercial Training. 36 (4), 2004,158:161.

[8]. A. Sippola, 'Developing culturally diverse organisations; a participative and empowerment-based method'. Women in Management Review. 22 (4), 2007, 253:273

[9]. G. T. Cummings, G. C.and Worley, Organisation development and change. $8^{\text {th }}$ edn. (Ohio. Thomson South-Western, 2005).

[10]. M. Attwood, et al,. Leading change a guide to whole systems working. (Bristol. The Policy Press, 2003)

[11]. B. Burnes, Managing change. A strategic approach to organisational dynamics. $2^{\text {nd }}$ edn. London. (Pitman Publishing. 1996)

[12]. W.E. Rosenbach, and R.L. Taylor, Contemporary issues in leadership. $5^{\text {th }}$ edn. (Colorado. Westview Press, 2001)

[13]. R. Pettinger, Contemporary strategic management. (New York. PALGRAVE MacMillan. 2004)

[14]. G. T. Cummings, and G. C. Worley, (2005) Organisation development and change. $8^{\text {th }}$ edn. (Ohio. Thomson South-Western. 2005)

[15]. M. Tayeb, Organisations and national culture: methodology considered.' Organisation Studies. 15 (3), 1994. $429: 446$

[16]. E. H. Schein, Organizational Culture and Leadership. (Jossey-Bass. San Francisco. 1985). 
[17]. N. M. Pless, and T.Maak, 'Building an inclusive diversity culture: principles, processes and practice'. Journal of Business Ethics, 54, 2004,129:147

[18]. A. Sippola, 'Developing culturally diverse organisations; a participative and empowerment-based method'. Women in Management Review. 22 (4), 2007, 253:273

[19]. E. H. Schein, Organisation culture and leadership. $2^{\text {nd }}$ edn. San Francisco. (Jossey-Bass Inc., Publishers. 1992)

[20]. D. Clifford, and M. Royce, 'Equality, Diversity, Ethics and Management in Social Work Education', Social Work Education, The International Journal. 27(1), 2007, $3: 18$

[21]. Ross \& Schneider, From Diversity to Equality: a business case for equal opportunities, (London. Pitman Publishing, 1992)

[22]. Rossett \& Bickham 'Diversity training', Training, no. 31, 1994, 40:46.

[23]. T. H. Cox, and S. Blake, S. "Managing cultural diversity: implications for organizational competitiveness", Academy of Management Executive, 5 (3), 1991, 45:56.

[24]. R. S. Allen, G. Dawson, K, Wheatly, and C. S. White, 'Perceived diversity and organisational performance'. Employee Relations. 30 (1), 2008, 20:33

[25]. R. Kandola, and J. Fullerton, Managing the mosaic. (Wiltshire. The Cromwell Press, 1994)

[26]. B. D'Netto, and A. S. Sohal, "Human resource practices and workforce diversity: an empirical assessment", International Journal of Manpower, Vol. 20 No. 8,1999. 530:547.

[27]. C. K. Patterson, C. K (2007) 'The impact of generational diversity in the workplace.' Generation Diversity. Vol. 15 No 3.

[28]. F. Luthans, Organisational behaviour. $7^{\text {th }}$ edn. (New York. McGraw-Hill, Inc, 1995)

[29]. J. McGarry, and B. O'Leary, Introduction: the macro-political regulation of ethnic conflict in the politics of ethnic conflict regulation. (London. Rutledge, 1993)

[30]. D. E. McHenry, Federalism in Africa: is it a solution to, or a cause of, ethnic problem?(Ohio. 1997)

[31]. A. R. Mustapha, "Coping with diversity: the Nigerian state in historical perspective" In AbdiIsmail Samatar and Ahmed I. Samatar (eds), The African State: reconsiderations. (Portsmouth. Heinemann, 2002)

[32]. P. T. Adujie, Quota system or federal character in Nigeria and affirmative action policy in America compared in (www.adujiewritings.blogspt.com, 2003)

[33]. P. P. Ekeh, and E. E. Osaghae, Federal character and federalism in Nigeria. (Ibadan. Heinemann Educational Books. 1989)

[34]. S. Groschl, and Doherty, Diversity management in practice. International Journal of Contemporary Hospitality management. 11 (6), 1999, 262:268.

[35]. S. E. Oyovbaire, "Structural change and political process in Nigeria". African Affairs, 82 (32), 1983, 3:28

[36]. P. P. Ekeh, and E. E. Osaghae, Federal character and federalism in Nigeria. (Ibadan. Heinemann Educational Books, 1989).

[37]. E. E. Osaghae, Federalism and the management of diversity in Africa. Identity, Culture and Politics. 5:(1 and 2), 2004, 162-178

[38]. E. E. Osaghae, Federalism and the management of diversity in Africa. Identity, Culture and Politics. 5:(1 and 2), 2004, 162-178

[39]. [39] E. E. Osaghae, Crippled giant: Nigeria since independence. (Bloomington. Indiana University Press, 1998)

[40]. R. Yin, Case study research: Design and methods. (London. Sage publication, 1994)

[41]. C. Glesne, Becoming qualitative researchers. An introduction. (Boston. Pearson Education, Inc. 2011)

[42]. S. O. Ogbemudia, Quota system in education placement and employment: is this still relevant in a capitalist and democratic society like Nigeria. A paper delivered at the second unity conference of Edo global organisation. Verona, Italy, on the 12-14 November, 2004 available at www.edo-nation.net/edog3.htm

[43]. A. R. Mustapha, "Ethnic structure, inequality and governance of the public sector in Nigeria". Democracy, Governance and Human Rights Programme Paper number 24 Nov. 2006. United Nations Research Institute for Social Development.

[44]. L. Ademolegun, J. Erero, and B. Oshionebo, "Federal character and management of the federal civil service and the military". Journal of Federalism. 21(4), 1991, 75:88.

[45]. S. E. Oyovbaire, "Structural change and political process in Nigeria". African Affairs, 82 (326), 1983, 3:28

[46]. P. B.Johnnie, Quota system of employment in strategic organisations in Nigeria. Humanomics. 13 (2). 1997, 59:79.

[47]. G. Magdaleno, and B. Kleiner, Global trends in managing cultural diversity. Cross Cultural Management. An International journal,3(4). 1996, 31: 36

[48]. M. Porter, What is strategy?, (Harvard Business Review, 1996) 